\title{
Percutaneous closure of atrial septal defects leads to normalisation of atrial and ventricular volumes
}

\author{
Karen SL Teo*1,2, Benjamin K Dundon,2, Payman Molaee ${ }^{1,2}$, \\ Kerry F Williams ${ }^{1}$, Angelo Carbone ${ }^{1}$, Michael A Brown ${ }^{1}$, \\ Matthew I Worthley ${ }^{1,2}$, Patrick J Disney ${ }^{1}$, Prashanthan Sanders ${ }^{1,2}$ and \\ Stephen G Worthley ${ }^{1,2}$
} \author{
University of Adelaide, Adelaide, South Australia, Australia \\ Email: Karen SL Teo* - karen.teo@adelaide.edu.au; Benjamin K Dundon - benjamin.dundon@adelaide.edu.au; \\ Payman Molaee - payman.molaee@adelaide.edu.au; Kerry F Williams - kerryfb@hotmail.com; \\ Angelo Carbone - angelo.carbone@adelaide.edu.au; Michael A Brown - michaelbrown@internode.on.net; \\ Matthew I Worthley - matthew.worthley@adelaide.edu.au; Patrick J Disney - disney_patrick@hotmail.com; \\ Prashanthan Sanders - prash.sanders@adelaide.edu.au; Stephen G Worthley - stephen.worthley@adelaide.edu.au \\ * Corresponding author
}

Address: ${ }^{1}$ Cardiovascular Research Centre, Royal Adelaide Hospital and The University of Adelaide, Adelaide, South Australia, Australia and ${ }^{2}$ The

Published: I December 2008

Journal of Cardiovascular Magnetic Resonance 2008, 10:55 doi:10.1 186/1532-429X-10-55

This article is available from: http://www.jcmr-online.com/content/10/1/55

(c) 2008 Teo et al; licensee BioMed Central Ltd.

This is an Open Access article distributed under the terms of the Creative Commons Attribution License (http://creativecommons.org/licenses/by/2.0), which permits unrestricted use, distribution, and reproduction in any medium, provided the original work is properly cited.
Received: 15 July 2008

Accepted: I December 2008

\begin{abstract}
Background: Percutaneous closure of atrial septal defects (ASDs) should potentially reduce right heart volumes by removing left-to-right shunting. Due to ventricular interdependence, this may be associated with impaired left ventricular filling and potentially function. Furthermore, atrial changes post-ASD closure have been poorly understood and may be important for understanding risk of atrial arrhythmia post-ASD closure. Cardiovascular magnetic resonance (CMR) is an accurate and reproducible imaging modality for the assessment of cardiac function and volumes. We assessed cardiac volumes pre- and post-percutaneous ASD closure using CMR.

Methods: Consecutive patients $(n=23)$ underwent CMR pre- and 6 months post-ASD closure. Steady state free precession cine CMR was performed using contiguous slices in both short and long axis views through the ASD. Data was collected for assessment of left and right atrial, ventricular end diastolic volumes (EDV) and end systolic volumes (ESV). Data is presented as mean $\pm \mathrm{SD}$, volumes as $\mathrm{mL}$, and paired t-testing performed between groups. Statistical significance was taken as $p<0.05$.

Results: There was a significant reduction in right ventricular volumes at 6 months post-ASD closure (RVEDV: $208.7 \pm$ 76.7 vs. $140.6 \pm 60.4 \mathrm{~mL}, \mathrm{p}<0.000 \mathrm{I}$ ) and RVEF was significantly increased (RVEF $35.5 \pm 15.5$ vs. $42.0 \pm 15.2 \%, p=0.025$ ). There was a significant increase in the left ventricular volumes (LVEDV $84.8 \pm 32.3 \mathrm{vs}$. $106.3 \pm 38.1 \mathrm{~mL}, \mathrm{P}=0.003$ and LVESV $37.4 \pm 20.9$ vs. $46.8 \pm 18.5 \mathrm{~mL}, p=0.016$ ). However, there was no significant difference in LVEF and LV mass post-ASD closure. There was a significant reduction in right atrial volumes at 6 months post-ASD closure (pre-closure I I $0.5 \pm 55.7$ vs. post-closure $90.7 \pm 69.3 \mathrm{~mL}, \mathrm{p}=0.019$ ). Although there was a trend to a decrease in left atrial volumes post-ASD closure, this was not statistically significant $(84.5 \pm 34.8 \mathrm{~mL}$ to $81.8 \pm 44.2 \mathrm{~mL}, \mathrm{p}=\mathrm{NS})$.
\end{abstract}

Conclusion: ASD closure leads to normalisation of ventricular volumes and also a reduction in right atrial volume. Further follow-up is required to assess how this predicts outcomes such as risk of atrial arrhythmias after such procedures. 


\section{Background}

Atrial septal defects (ASDs) are the most common congenital cardiac malformation first diagnosed in adults and account for approximately $10 \%$ of all congenital heart lesions $[1,2]$. Patients with a significant shunt experience symptoms over time with effort dyspnoea seen in about $30 \%$ of patients by the third decade and in over $75 \%$ of patients by the fifth decade [3]. The natural course of untreated atrial septal defects often leads to a shortened life expectancy compared to healthy subjects [3]. Longstanding right heart, pulmonary arterial and venous volume overload and dilatation in the setting of an ASD may lead to the development of right heart failure, arrhythmia, thromboembolic events, pulmonary vascular obstructive disease [3-5]. In adults with an ASD and chronic right atrial volume overload, there may be long-term arrhythmias which do not seem to be affected by closure of the defect [6]. In patients aged greater than 40 years with atrial septal defects closed surgically, $60 \%$ of these patients develop atrial arrhythmias late after surgery [7]. This may be contributed by chronic right atrial stretch which causes electrophysiological alterations that persist beyond ASD closure [8].

Surgical repair of atrial septal defects has previously been shown to have excellent results in both medium and long term studies [9]. In one retrospective study of patients over 40 years of age with isolated atrial septal defects, surgical repair increased long term survival, with adjusted 10 year survival rate of $95 \%$ compared to $84 \%$ in the medically treated group [10]. In addition, surgical treatment prevented functional deterioration due to heart failure. However, surgical repair is associated with significant morbidity from peri-operative complications such as pleural effusions, sepsis and pericardial tamponade [11], although the long-term outcome after surgical ASD closure at a young age is much better than surgical closure at adult age [9].

Many adults with secundum ASDs are now able to have these defects closed percutaneously using septal occluder devices such as with the Amplatzer Septal Occluder (ASO), a self-expanding circular double disc that has a conjoint waist containing polytetrafluoroethylene (PTFE) and a nitinol mesh. This device has become an accepted alternative to surgical repair with studies comparing ASO device closure to surgical closure showing decreased complication rates, shorter hospital stays and greater costeffectiveness [12]. Percutaneous closure of atrial septal defects should reduce right heart volumes by removing left-to-right shunting and thus, lead to symptomatic improvement and increased exercise capacity [12-14]. However, the effects on left ventricular volumes and function are less well described. Ventricular interdependence is a described phenomenon and suggests that a left ven- tricular effect may well be expected post-ASD closure. Furthermore, atrial changes post-ASD closure have been poorly understood and it is unclear whether there is a significant decrease in atrial arrhythmia post-ASD closure. Thus, atrial changes post-closure may be important for understanding the risk of atrial arrhythmia post-ASD closure.

Cardiovascular magnetic resonance (CMR) is an accurate and reproducible imaging modality for the assessment of cardiac function and volumes. Thus, we sought to use CMR to assess ventricular and atrial volumes directly to document structural changes post-ASD closure.

\section{Methods Subjects}

Consecutive patients with secundum atrial septal defects diagnosed on transthoracic and transoesophageal echocardiography with significant left to right shunt (>1.5:1) underwent CMR pre-ASD closure and 6 months post- ASD closure with the Amplatzer Septal Occluder. Only patients in sinus rhythm pre-ASD closure were included.

\section{CMR}

All CMR studies were performed with subjects in the supine position using a 1.5 Tesla MRI scanner (Siemens Sonata, Germany) and a phased array surface coil. For the ventricular image set, long-axis reference views were used for positioning 8 to 12 perpendicular ventricular shortaxis slices from the level of the mitral valve to the left ventricular apex. Images were obtained during end-expiratory breath-hold (8 to 10 seconds) with retrospectively ECGgated True-FISP (Fast Imaging with Steady-State Precession) sequences (Image matrix $256 \times 150$, field of view $380 \mathrm{~mm}$, repetition time $52.05 \mathrm{~ms}$, echo time $1.74 \mathrm{~ms}$ and flip angle $70^{\circ}$ ). Ventricular short axis slice thickness was 6 $\mathrm{mm}$ with intersection gaps of $4 \mathrm{~mm}$, based on previous published studies $[15,16]$. For the atrial image set, multiple contiguous slices in both short (bi-atrial) and horizontal long axis views (four chamber) were obtained through the ASD, with slice thickness of $6 \mathrm{~mm}$ and no intersection gap.

\section{CMR analysis}

Ventricular and atrial analyses were performed off-line with a proprietary software program (Argus software, Siemens Medical Solutions, Germany). For the left ventricular (LV) data set, short-axis endocardial and epicardial contours were manually traced in end-diastole (at start of R-wave) and in end-systole (smallest cavity area). Papillary muscles and trabeculations were excluded from the ventricular volume and were included if contiguous with the myocardial mass. The basal slice was selected as the slice where the blood volume was surrounded by $>50 \%$ of 
ventricular myocardium $[15,16]$. For the right ventricular (RV) data set, one observer manually traced the endocardial contours at end-diastole and at end-systole. The selection of the RV basal slice was based on published methods where, if the pulmonary valve was seen, only the portion of the volume below the level of the pulmonary valve was included [16]. Both LV and RV end-diastolic and endsystolic cavity surface areas were summed up and volumes: end-diastolic (EDV) and end-systolic (ESV) estimated by multiplying with interslice intervals as per Simpson's rule. Ejection fraction (EF) was calculated as EF $=(\mathrm{EDV}-\mathrm{ESV}) / \mathrm{EDV} \times 100(\%)$ and left ventricular mass as LV mass $=1.05 \times$ (epicardial volume - endocardial volume).

A true three-dimensional atrial volume assessment technique was used, in which the endocardial borders were manually traced for both left and right atria in the horizontal long axis (four chamber) views in ventricular endsystole when atrial volume is maximal [17]. Borders of left atrium were defined as the plane of the mitral valve and the visually apparent juncture of left atrium with pulmonary veins. Borders of right atrium were defined as the plane of the tricuspid valve and the juncture with the vena cavae. The atrial appendage was included if present on the images. Atrial volumes were calculated as a sum of atrial cavity areas with interslice intervals using a modification of Simpson's rule.

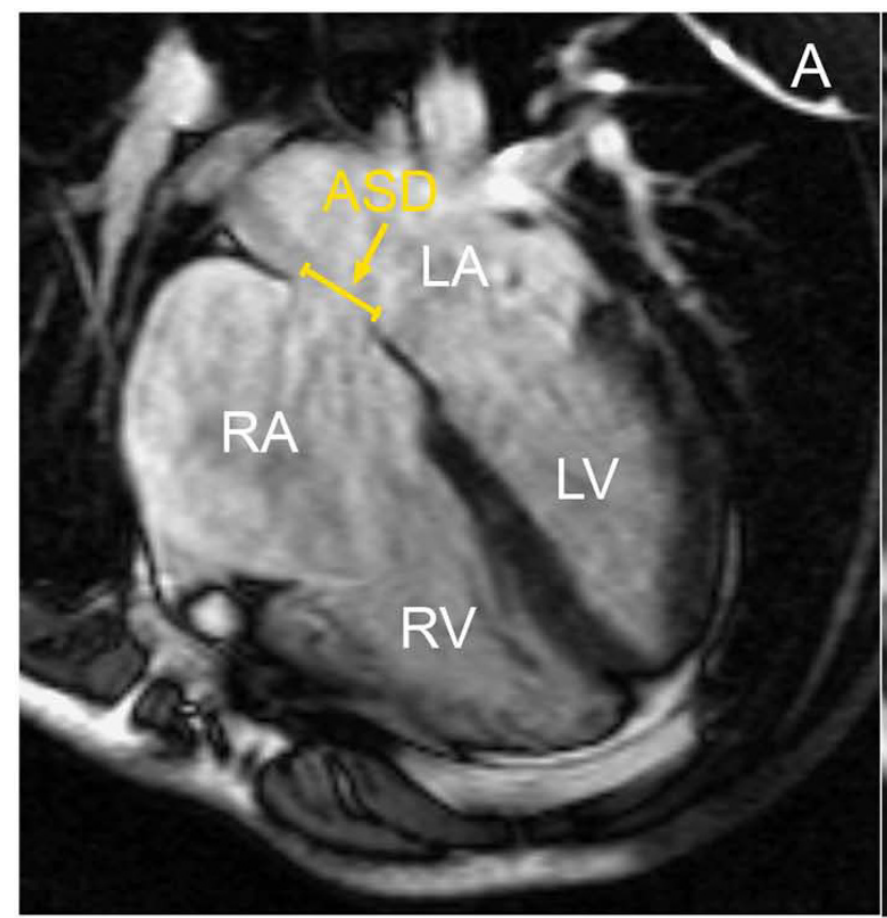

\section{ASD device implantation}

All ASDs were closed with the Amplatzer Septal occluder (AGA medical corporation). Procedures were performed under general anaesthesia with transoesophageal echocardiographic guidance and fluoroscopy. A sizing balloon was used to determine the stretched diameter of the ASD before selection and deployment of ASO device, as previously described [18]. In brief, a Meditech balloon (Boston Scientific, Watertown, MA) sized 20 or $27 \mathrm{~mm}$ in this series is used. This balloon is inflated within the left atrium and firm continuous pressure applied to pull it into the atrial septum, using TOE guidance. The diameter at which the balloon just gets through the atrial septal defect is the stretched balloon diameter (SBD).

\section{Follow-up CMR}

CMR was repeated at 6 months from the time of the ASD closure, with the full dataset obtained to re-assess cardiac volumes and function (see Figures 1 and 2).

\section{Reproducibility}

Intra- and inter- observer variability was assessed for the left and right atrial and ventricular parameters.

\section{Statistical analysis}

Data is presented as mean \pm standard deviation. Comparison of cardiac volumes pre- and 6 months post-ASD closure was performed with paired $t$ testing between groups.

\section{Figure I}

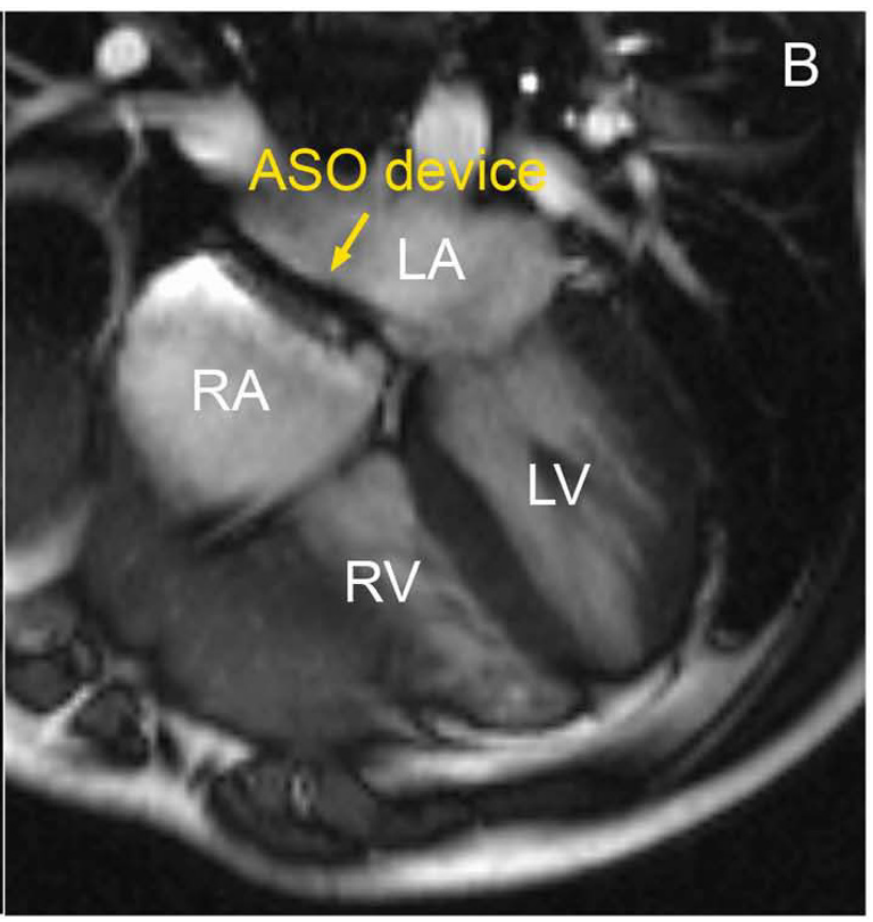

Four chamber CMR views showing the ASD pre- (panel A) and post-closure with the Amplatzer Septal Occluder (ASO) device (panel $B$ ). $R A=$ right atrium, $L A=$ left atrium, $R V=$ right ventricle and $L V=$ left ventricle. 


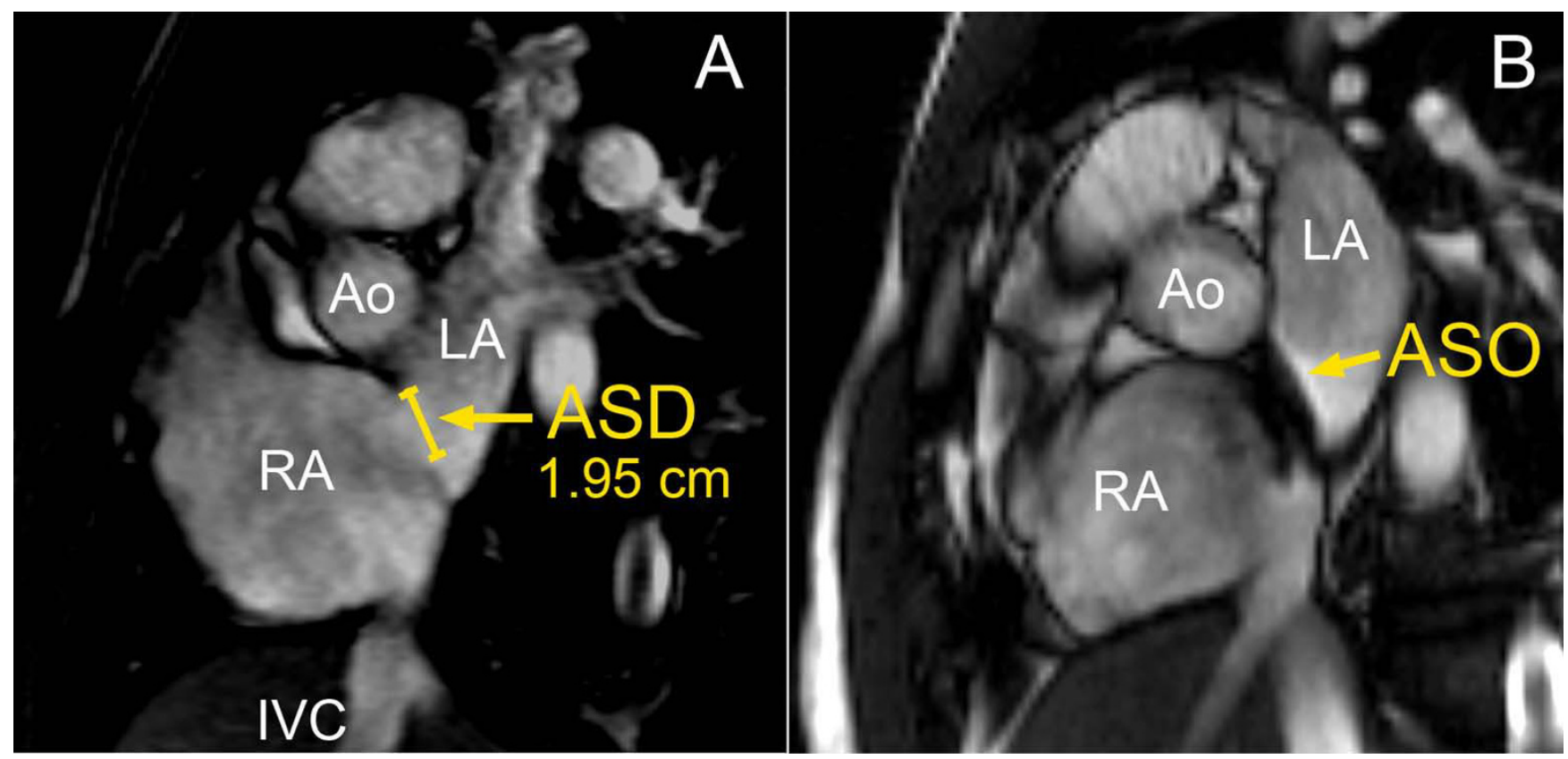

Figure 2

Bi-atrial short axis views showing the ASD (same patient as Figure I) pre- (panel A) and post-closure with the ASO (panel B). $\mathrm{RA}=$ right atrium, $\mathrm{LA}=$ left atrium, $\mathrm{Ao}=$ aorta and $\mathrm{IVC}=$ inferior vena cava).

Statistical significance was taken as $\mathrm{p}<0.05$. Inter and intraobserver variability was assessed using the Bland and Altman method [19] as well as intraclass correlation coefficients.

\section{Results}

A total of 23 patients were included in the study (mean age $51.2 \pm$ years, 20 females and 3 males). Two patients who went on to surgical closure of their ASDs due to size of the defect were excluded from the analysis and one patient did not attend the follow up scan. Follow up CMR studies were obtained in 20 patients.

\section{Atrial changes}

There was a significant reduction in right atrial volumes at 6 months post-ASD closure (pre-closure $110.5 \pm 55.7$ vs. post-closure $90.7 \pm 69.3 \mathrm{~mL}, \mathrm{p}=0.019)$. Although there was a trend to a decrease in left atrial volumes post-ASD closure, this was not statistically significant $(84.5 \pm 34.8$ $\mathrm{mL}$ to $81.8 \pm 44.2 \mathrm{~mL}, \mathrm{p}=\mathrm{NS}$ ).

\section{Ventricular changes}

There was a significant reduction in right ventricular volumes at 6 months post-ASD closure (RVEDV: $208.7 \pm 76.7$ vs. $140.6 \pm 60.4 \mathrm{~mL}, \mathrm{p}<0.0001)$ and RVEF was significantly increased (RVEF $35.5 \pm 15.5$ vs. $42.0 \pm 15.2 \%$, p = $0.025)$. Left ventricular volumes were significantly increased (LVEDV $84.8 \pm 32.3$ vs. $106.3 \pm 38.1 \mathrm{~mL}, \mathrm{p}=$ 0.003 and LVESV $37.4 \pm 20.9$ vs. $46.8 \pm 18.5 \mathrm{~mL}, \mathrm{p}=$
0.016). There was no significant difference in LVEF and LV mass post-ASD closure (See Table 1).

Indexed right ventricular volumes (to body surface area) pre-ASD closure were greater than aged-matched controls at baseline (RV EDV/BSA $130.1 \pm 23.8$ vs. $65.9 \pm 15.9, \mathrm{p}<$ 0.0001 and RV ESV/BSA $77.7 \pm 31.1$ vs. $33.9 \pm 24.1$, p < $0.0001)$, but were not significantly different to agedmatched controls post-ASD closure (RV EDV/BSA $84.6 \pm$ 36.3 vs. $65.9 \pm 15.9, \mathrm{p}=0.06$ and RV ESV/BSA $47.6 \pm 24.1$ vs. $33.9 \pm 16.5, \mathrm{p}=0.07)$. Indexed left ventricular volumes and mass were not significantly different to aged-matched controls pre- or post- ASD closure (See Table 2).

\section{Reproducibility}

Interobserver variability

Intraclass correlation coefficients between 2 independent observers for RV and LV parameters were: RV EDV 0.93, RV ESV 0.89, LV EDV 0.96, LV ESV 0.89, LV mass 0.84, RA volume 0.92, LA volume 0.87, RV EF 0.70, LVEF 0.94. Results from the Bland and Altman analyses for interobserver variability for LV and RV are presented as mean, the difference between the means \pm 2 SD: LV EDV mean 86.2, difference $6.1 \pm 22.6 \mathrm{~mL}$, LV EF mean 62.9, difference -4.8 $\pm 24.6 \%$, RVEDV mean 211.0, difference $19.6 \pm 57.4 \mathrm{~mL}$ and RV EF mean 43.2, difference $10.1 \pm 15.6 \%$. Interobserver mean and difference between means of atrial volumes \pm 2 SD were: LA volume 146.8, difference - $2.2 \pm 25.5$ 
Table I: CMR data pre and post-percutaneous ASD closure.

\begin{tabular}{|c|c|c|c|c|}
\hline & Pre-closure & Post-Closure & Change (\%) & P-value \\
\hline RV EDV (mL) & $208.7 \pm 76.7$ & $140.6 \pm 60.4$ & $\downarrow 32.6$ & $<0.0001$ \\
\hline RV ESV (mL) & $134.0 \pm 63.7$ & $81.6 \pm 41.5$ & $\downarrow 39.1$ & $<0.0001$ \\
\hline RV EF (\%) & $35.5 \pm 15.5$ & $42.0 \pm 15.2$ & $\uparrow 18.3$ & 0.025 \\
\hline LV EDV (mL) & $84.9 \pm 32.3$ & $106.3 \pm 38.1$ & $\uparrow 25.2$ & 0.003 \\
\hline LV ESV (mL) & $37.3 \pm 20.9$ & $46.8 \pm 18.5$ & $\uparrow 25.4$ & 0.016 \\
\hline LV EF (\%) & $61.7 \pm 12.8$ & $58.2 \pm 9.0$ & $\downarrow 5.7$ & NS \\
\hline LV mass (g) & $91.2 \pm 29.5$ & $103.0 \pm 48.0$ & $\uparrow 12.9$ & NS \\
\hline RA vol. (mL) & $110.5 \pm 55.7$ & $90.7 \pm 69.3$ & $\downarrow 17.9$ & 0.019 \\
\hline LA vol. (mL) & $84.5 \pm 34.8$ & $81.8 \pm 44.2$ & $\downarrow 3.2$ & NS \\
\hline
\end{tabular}

$\mathrm{RV}=$ right ventricle, $\mathrm{LV}=$ left ventricle, $\mathrm{RA}=$ right atrial, $\mathrm{LA}=$ left atrial, $\mathrm{EDV}=$ end-diastolic volume, $\mathrm{ESV}=$ end-systolic volume, $\mathrm{EF}=$ ejection fraction, vol. $=$ volume, $\mathrm{NS}=$ non-significance.

$\mathrm{mL}$ and $\mathrm{RA}$ volume mean 128.7 , difference $-4.7 \pm 40.4$ $\mathrm{mL}$.

\section{Intraobserver variability}

Intraclass correlation coefficients for intraobserver variability for RV and LV parameters were RV EDV 0.89, RV ESV 0.85, LV EDV 0.95, LV ESV 0.98, RA volume 0.98, LA volume 0.84, RV EF 0.77, LV EF 0.91.

\section{Discussion}

We have shown that percutaneous ASD closure leads to a reduction in $\mathrm{RV}$ volumes, in association with an increase in $\mathrm{LV}$ volumes by CMR. This was associated with an improvement in RVEF, but no change in LVEF. Furthermore, for the first time, we have seen a significant decrease in right atrial volumes post-ASD closure by CMR, but a non-significant change in left atrial volumes.

In our study, we have used CMR to obtain a full volume data set for both ventricles and atria. CMR has been shown to be safe post-cardiovascular implants [20] and has become the gold standard in the assessment of left and right ventricular volumes, function and mass with excellent accuracy and reproducibility $[15,16,21,22]$. Furthermore, compared to echocardiography, CMR has the advantage in the assessment of right ventricular volumes, given the non-geometric shape of the right ventricle, which makes quantification of right ventricular volume difficult by echocardiography. Previous studies on the effect of ASD closure on chamber volumes have mainly been performed using echocardiography although more recently, there have been a couple of studies that have looked at atrial and ventricular changes using CMR $[23,24]$.

Atrial assessments of atrial dimensions using a one or twodimensional parameter or estimation of atrial volume based on two-dimensional image algorithms have limitations. Echocardiography M-mode atrial dimension as a measure of atrial size assumes that a direct relationship between this one-dimensional measurement and atrial volume. Biplane two-dimensional echocardiography assumes an elliptical geometry of the atria [25]. These clearly are not exact, due to the variable and non-uniform geometry of the atria with significant differences demonstrated in the measurement of atrial volumes using biplane area length and biplane modified Simpson methods [26]. Atrial enlargement may also be asymmetrical. CMR volume assessment of the atrium with cine imaging requires no assumptions about the geometry of the atria and has become an accepted standard for the determination of atrial volumes [27-29]. We therefore obtained a true three-dimensional atrial volume assessment technique in which the atrial borders were traced for both left and right atria in the horizontal long axis (four chamber) views in ventricular end-systole when atrial volume is maximal [17].

\section{ASD closure}

Echocardiography studies in adult and paediatric patients with closure of atrial septal defects have shown a reduction in right atrial areas and ventricular volumes after ASD

Table 2: Comparison of indexed RV and LV volumes to aged-matched controls

\begin{tabular}{lllll}
\hline & Pre-closure $\left(\mathbf{m L} / \mathbf{m}^{2}\right)$ & Post-closure $\left(\mathbf{m L} / \mathbf{m}^{2}\right)$ & Aged-match $\left(\mathbf{m L} / \mathbf{m}^{2}\right)$ & Unpaired t-test $(\mathbf{v s . ~ p o s t - c l o s u r e ) ~}$ \\
\hline RV EDV/BSA & $130 \pm 32.8$ & $84.6 \pm 36.3$ & $65.9 \pm 15.9$ & 0.07 \\
RV ESV/BSA & $77.7 \pm 31.1$ & $47.6 \pm 24.1$ & $33.9 \pm 16.5$ & 0.07 \\
LV EDV/BSA & $51.8 \pm 12.6$ & $64.8 \pm 16.1$ & $59.6 \pm 14.3$ & $\mathrm{NS}$ \\
LV ESV/BSA & $21.0 \pm 10.8$ & $26.4 \pm 10.2$ & $25.9 \pm 8.1$ & $\mathrm{NS}$ \\
LV mass/BSA & $50.6 \pm 13.4$ & $58.6 \pm 29.5$ & $49.8 \pm 9.1$ & $\mathrm{NS}$ \\
\hline
\end{tabular}


closure both surgically [30] and percutaneously [24,3135]. However, there is a subgroup of patients where right atrial and right ventricular sizes do not normalize. This has been reported in adult patients of $28 \%$ for RA [34] and 29\% for RV 1 year after percutaneous closure [33]. Persistent right atrial and ventricular enlargement is associated with higher age at closure [31-34]. However, even in the group of patients who had ASD closure during childhood, there was a group ( $>20 \%$ ) with persistent RV dilatation and RA enlargement [9].

RV ejection fraction has been shown to decrease after surgical ASD repair. The possible causes of this were thought to include a true reduction in RV ejection fraction postoperatively, less volume overload of the right ventricle, less paradoxical septal motion or an inaccuracy in echocardiography methods for evaluating RV ejection fraction [30]. RV systolic and diastolic function may be supra normal due to the increased pulmonary blood flow, while those of the left ventricle may be within normal range [36]. No changes were found in left ventricular (LV) volumes and ejection fraction in this study [30]. Global LV function has been shown to improve after percutaneous ASD closure. In a recent study, myocardial performance index (MPI), a measure of combined systolic and diastolic function [37] was significantly improved for both RV and LV [38] in patients who underwent percutaneous ASD closure. The same index measured post-surgical ASD closure has been shown to be not significantly different [37] and previous investigators have indicated that this may be contributed to by cardiopulmonary bypass $[30,36]$, which is avoided by percutaneous closure.

\section{Percutaneous ASD closure}

Cardiac remodelling post-ASD closure has been shown to be an early event, with reduction in right ventricular and atrial sizes occurring in the first week post-closure and that after 4 months no changes were observed [39]. Significant changes also occurred in the left ventricle, with increase in LV dimensions post-closure, but without changes in LA dimensions.

Because of its shape, quantitative echocardiographic methods to evaluate RV volumes have been difficult and thus limited to 2-D measurements. Right-sided cardiac parameters measured have included RV and RA diameters, RVOT diameters and the assessment of paradoxical septal motion $[13,32,33,38]$. Even at one month post-ASD closure, mean RV size and mean RVOT diameter was significantly reduced to within normal limits while mean right atrial length showed a trend toward shortening at one month and reached significance at 6 months [33]. At one year, a third of patients demonstrated persistent RV enlargement [33]. Our data with more accurate assessment of right atrial dimensions clearly shows a volume reduction in all patients.
Closure of secundum ASD results in decreased indexed RV volume (as measured by transthoracic echocardiography) comparable to that in control subjects at 24 months following closure. However indexed RA area remained greater than in the control group. Decrease in indexed RA area over the first 12 months of follow-up was related to young age at time of closure [31].

Global LV function has been shown to improve after percutaneous ASD closure. In a recent study, myocardial performance index (MPI), a measure of combined systolic and diastolic function [37] was significantly improved for both RV and LV [38] in patients who underwent percutaneous ASD closure. The same index measured post-surgical ASD closure has been shown to be not significantly different [40] and previous investigators have indicated that this may be contributed to by cardiopulmonary bypass $[30,36]$, which is avoided by percutaneous closure. In our data set however, there was no significant change in LVEF although both LVEDV and LVESV increased.

\section{Interventricular dependence}

Ventricular interdependence has been well described in echocardiography studies and highlights the important role of the inter-ventricular septum in RV and LV function. In RV volume overload, the septum bulges into and encroaches on the LV cavity and leads to impairment of $\mathrm{LV}$ filling. The right ventricle is also more compliant than the left ventricle so the left ventricle is relatively under filled. The mechanisms for decreased LV performance associated with RV volume overload include the mechanical disadvantage of a non-circular short axis configuration and changes in chamber and myocardial preload [41].

Reduced LV systolic function associated with RV volume overload has been described [42-44]. One echocardiographic study has reported the occurrence of adverse ventricular interdependence associated with RV volume overload in patients with ASDs [41] in which the septum bulges into and encroaches on the LV cavity and leads to impairment of LV filling. Since the right ventricle is also more compliant than the left ventricle, the left ventricle is relatively under filled. However, the reversibility of this ventricular dysfunction after elimination of the RV volume overload with surgical closure has not been consistently demonstrated [43]. This may reflect surgical confounding factors that affect LV function, including pericardectomy, cardiopulmonary bypass and postoperative alterations in preload, afterload and heart rate [41].

Percutaneous device closure of the ASD avoids the confounding factors caused by surgery. In a study of 34 patients, LV ejection fraction obtained by echocardiography improved significantly from 54.9 to $62.1 \%$ (P < $0.001)[41]$. 
In our study, left ventricular volumes were reduced as compared to normal values, but increased 6 months postclosure of the ASD. This is similar to a recent study which looked at left ventricular dimensions with CMR post-ASD closure [45]. In addition, they found NT-proBNP concentrations were within the normal range pre-ASD closure, but increased early after interventional closure and was associated with the increase in left ventricular dimensions as assessed by CMR [45]. However, they failed to evaluate atrial volumetric changes pre- and post- ASD closure.

\section{Limitations}

In this study, formal assessment of shunt calculation by Qp:Qs was not performed on the baseline CMR studies initially. Therefore, we were unable to assess any relationships between degree of left to right shunting with changes in cardiac volumes after percutaneous ASD closure.

\section{Conclusion}

Percutaneous ASD closure leads to normalisation of both $\mathrm{RV}$ and $\mathrm{LV}$ volumes using CMR. With a true volumetric CMR technique, we note that RA volume reduces significantly although the small LA volume reduction was not significant. This may have important implications for future risk of atrial arrhythmogenicity.

\section{Competing interests}

The authors declare that they have no competing interests.

\section{Authors' contributions}

KST participated in the study design, CMR data acquisition, analysis and manuscript preparation. BKD and AC participated in data analysis and manuscript revision. PM and KW were involved in CMR acquisition. MB, MIW, PJD, PS contributed to manuscript revision. SGW conceived the study, supervised the CMR acquisition and revised the manuscript. All authors read and approved the final manuscript.

\section{References}

I. Hoffman JI, Kaplan S: The incidence of congenital heart disease. J Am Coll Cardiol 2002, 39( I 2): 1890-900.

2. Hoffman Jl, Kaplan S, Liberthson RR: Prevalence of congenital heart disease. Am Heart J 2004, 147(3):425-39.

3. Campbell M: Natural history of atrial septal defect. Br Heart J 1970, 32(6):820-6.

4. Steele PM, Fuster V, Cohen M, Ritter DG, McGoon DC: Isolated atrial septal defect with pulmonary vascular obstructive disease - long-term follow-up and prediction of outcome after surgical correction. Circulation 1987, 76(5): 1037-42.

5. Jones HR Jr, Caplan LR, Come PC, Swinton NW Jr, Breslin DJ: Cerebral emboli of paradoxical origin. Ann Neurol 1983, I3(3):314-9.

6. Murphy JG, Gersh BJ, McGoon MD, Mair DD, Porter C], Ilstrup DM, McGoon DC, Puga FJ, Kirklin JW, Danielson GK: Long-term outcome after surgical repair of isolated atrial septal defect. Follow-up at 27 to 32 years. N Engl J Med 1990, 323(24): 1645-50

7. Berger F, Vogel M, Kramer A, Alexi-Meskishvili V, Weng Y, Lange PE, Hetzer R: Incidence of atrial flutter/fibrillation in adults with atrial septal defect before and after surgery. Ann Thorac Surg 1999, 68(I):75-8.

8. Morton JB, Sanders P, Vohra JK, Sparks PB, Morgan JG, Spence SJ, Grigg LE, Kalman JM: Effect of chronic right atrial stretch on atrial electrical remodeling in patients with an atrial septal defect. Circulation 2003, 107(13): 1775-82.

9. Roos-Hesselink JW, Meijboom FJ, Spitaels SE, van Domburg R, van Rijen EH, Utens EM, Bogers AJ, Simoons ML: Excellent survival and low incidence of arrhythmias, stroke and heart failure long-term after surgical ASD closure at young age. A prospective follow-up study of 2I-33 years. Eur Heart $J$ 2003, 24(2): 190-7.

10. Konstantinides S, Geibel A, Olschewski M, Görnandt L, Roskamm H, Spillner G, Just H, Kasper W: A comparison of surgical and medical therapy for atrial septal defect in adults. N Engl J Med 1995, 333(8):469-73.

II. Galal MO, Wobst A, Halees Z, Hatle L, Schmaltz AA, Khougeer F, De Vol E, Fawzy ME, Abbag F, Fadley F, et al.: Peri-operative complications following surgical closure of atrial septal defect type II in 232 patients - a baseline study. Eur Heart J 1994, I5(10): $138 \mid-4$

12. Du ZD, Hijazi ZM, Kleinman CS, Silverman NH, Larntz K: Comparison between transcatheter and surgical closure of secundum atrial septal defect in children and adults: results of a multicenter nonrandomized trial. J Am Coll Cardiol 2002, 39(II):1836-44.

13. Brochu MC, Baril JF, Dore A, Juneau M, De Guise P, Mercier LA: Improvement in exercise capacity in asymptomatic and mildly symptomatic adults after atrial septal defect percutaneous closure. Circulation 2002, 106(14): 182I-6.

14. Giardini A, Donti A, Specchia S, Formigari R, Oppido G, Picchio FM: Long-term impact of transcatheter atrial septal defect closure in adults on cardiac function and exercise capacity. Int J Cardiol 2007, I 24(2): 179-I82.

15. Lorenz CH, Walker ES, Morgan VL, Klein SS, Graham TP Jr: Normal human right and left ventricular mass, systolic function, and gender differences by cine magnetic resonance imaging. J Cardiovasc Magn Reson 1999, I(I):7-2I.

16. Alfakih K, Plein S, Thiele H, Jones T, Ridgway JP, Sivananthan MU: Normal human left and right ventricular dimensions for MRI as assessed by turbo gradient echo and steady-state free precession imaging sequences. J Magn Reson Imaging 2003, I 7(3):323-9.

17. Hauser TH, McClennen S, Katsimaglis G, Josephson ME, Manning WJ, Yeon SB: Assessment of left atrial volume by contrast enhanced magnetic resonance angiography. J Cardiovasc Magn Reson 2004, 6(2):49I-7.

18. Harper RW, Mottram PM, McGaw DJ: Closure of secundum atrial septal defects with the Amplatzer septal occluder device: techniques and problems. Catheter Cardiovasc Interv 2002, 57(4):508-24.

19. Bland JM, Altman DG: Statistical methods for assessing agreement between two methods of clinical measurement. Lancet 1986, I (8476):307-10.

20. Prasad SK, Pennell DJ: Safety of cardiovascular magnetic resonance in patients with cardiovascular implants and devices. Heart 2004, 90(II): 124I-4.

21. Grothues F, Smith GC, Moon JC, Bellenger NG, Collins P, Klein HU, Pennell DJ: Comparison of interstudy reproducibility of cardiovascular magnetic resonance with two-dimensional echocardiography in normal subjects and in patients with heart failure or left ventricular hypertrophy. Am J Cardiol 2002, 90(I):29-34.

22. Grothues F, Moon JC, Bellenger NG, Smith GS, Klein HU, Pennell DJ: Interstudy reproducibility of right ventricular volumes, function, and mass with cardiovascular magnetic resonance. Am Heart J 2004, 147(2):218-23.

23. Burgstahler C, Wöhrle J, Kochs M, Nusser T, Löfler C, Kunze M, Höher M, Gawaz MP, Hombach V, Merkle N: Magnetic resonance imaging to assess acute changes in atrial and ventricular parameters after transcatheter closure of atrial septal defects. J Magn Reson Imaging 2007, 25(6): I I 36-40.

24. Schoen SP, Kittner T, Bohl S, Braun MU, Simonis G, Schmeisser A, Strasser RH: Transcatheter closure of atrial septal defects improves right ventricular volume, mass, function, pulmo- 
nary pressure, and functional class: a magnetic resonance imaging study. Heart 2006, 92(6):821-6.

25. Kircher B, Abbott JA, Pau S, Gould RG, Himelman RB, Higgins CB, Lipton MJ, Schiller NB: Left atrial volume determination by biplane two-dimensional echocardiography: validation by cine computed tomography. Am Heart J |99|, I2I(3 Pt I):864-7I.

26. Jiamsripong P, Honda T, Reuss CS, Hurst RT, Chaliki HP, Grill DE, Schneck SL, Tyler R, Khandheria BK, Lester SJ: Three methods for evaluation of left atrial volume. Eur J Echocardiogr 2007.

27. Jarvinen VM, Kupari MM, Hekali PE, Poutanen VP: Right atrial MR imaging studies of cadaveric atrial casts and comparison with right and left atrial volumes and function in healthy subjects. Radiology 1994, I 9 I(I): 137-42.

28. Jarvinen VM, Kupari MM, Poutanen VP, Hekali PE: Right and left atrial phasic volumetric function in mildly symptomatic dilated and hypertrophic cardiomyopathy: cine MR imaging assessment. Radiology 1996, I 98(2):487-95.

29. Sievers B, Kirchberg S, Addo M, Bakan A, Brandts B, Trappe HJ: Assessment of left atrial volumes in sinus rhythm and atrial fibrillation using the biplane area-length method and cardiovascular magnetic resonance imaging with TrueFISP. J Cardiovasc Magn Reson 2004, 6(4):855-63.

30. Shaheen J, Alper L, Rosenmann D, Klutstein MW, Falkowsky G, Bitran $D$, Tzivoni D: Effect of surgical repair of secundum-type atrial septal defect on right atrial, right ventricular, and left ventricular volumes in adults. Am J Cardiol 2000, 86 (I 2): I395-7.

31. Kort HW, Balzer DT, Johnson MC: Resolution of right heart enlargement after closure of secundum atrial septal defect with transcatheter technique. J Am Coll Cardiol 200I, 38(5): $\mid 528-32$.

32. Du ZD, Cao QL, Koenig P, Heitschmidt M, Hijazi ZM: Speed of normalization of right ventricular volume overload after transcatheter closure of atrial septal defect in children and adults. Am J Cardiol 200I, 88( I 2): |450-3.

33. Veldtman GR, Razack V, Siu S, El-Hajj H, Walker F, Webb GD, Benson LN, McLaughlin PR: Right ventricular form and function after percutaneous atrial septal defect device closure. J Am Coll Cardiol 200I, 37(8):2108-13.

34. Thilen U, Persson S: Closure of atrial septal defect in the adult. Cardiac remodeling is an early event. Int J Cardiol 2006, I 08(3):370-5.

35. Schussler JM, Anwar A, Phillips SD, Roberts BJ, Vallabhan RC, Grayburn PA: Effect on right ventricular volume of percutaneous Amplatzer closure of atrial septal defect in adults. Am / Cardiol 2005, 95(8):993-5.

36. Dhillon $\mathrm{R}$, Josen $\mathrm{M}$, Henein $\mathrm{M}$, Redington A: Transcatheter closure of atrial septal defect preserves right ventricular function. Heart 2002, 87(5):46I-5.

37. Eidem BW, Tei C, O'Leary PW, Cetta F, Seward JB: Nongeometric quantitative assessment of right and left ventricular function: myocardial performance index in normal children and patients with Ebstein anomaly. I Am Soc Echocardiogr 1998, I I(9):849-56.

38. Salehian O, Horlick E, Schwerzmann M, Haberer K, McLaughlin P, Siu SC, Webb G, Therrien J: Improvements in cardiac form and function after transcatheter closure of secundum atrial septal defects. J Am Coll Cardiol 2005, 45(4):499-504.

39. Thilen U, Berlind S, Varnauskas E: Atrial septal defect in adults. Thirty-eight-year follow-up of a surgically and a conservatively managed group. Scand Cardiovasc ] 2000, 34(I):79-83.

40. Eidem BW, O'Leary PW, Tei C, Seward JB: Usefulness of the myocardial performance index for assessing right ventricular function in congenital heart disease. Am J Cardiol 2000, 86(6):654-8

4I. Walker RE, Moran AM, Gauvreau K, Colan SD: Evidence of adverse ventricular interdependence in patients with atrial septal defects. Am J Cardiol 2004, 93(I I): I374-7.

42. Weyman AE, Wann S, Feigenbaum H, Dillon JC: Mechanism of abnormal septal motion in patients with right ventricular volume overload: a cross-sectional echocardiographic study. Circulation 1976, 54(2): I79-86.

43. Davies H, Oliver GC, Rappoport WJ, Gazetopoulos N: Abnormal left heart function after operation for atrial septal defect. $\mathrm{Br}$ Heart J 1970, 32(6):747-53.
44. Popio KA, Gorlin R, Teichholz LE, Cohn PF, Bechtel D, Herman MV: Abnormalities of left ventricular function and geometry in adults with an atrial septal defect. Ventriculographic, hemodynamic and echocardiographic studies. Am J Cardiol 1975, 36(3):302-8.

45. Weber M, Dill T, Deetjen A, Neumann T, Ekinci O, Hansel J, Elsaesser $A$, Mitrovic $V$, Hamm C: Left ventricular adaptation after atrial septal defect closure assessed by increased concentrations of $\mathbf{N}$-terminal pro-brain natriuretic peptide and cardiac magnetic resonance imaging in adult patients. Heart 2006, 92(5):67I-5.
Publish with Biomed Central and every scientist can read your work free of charge

"BioMed Central will be the most significant development for disseminating the results of biomedical research in our lifetime. "

Sir Paul Nurse, Cancer Research UK

Your research papers will be:

- available free of charge to the entire biomedical community

- peer reviewed and published immediately upon acceptance

- cited in PubMed and archived on PubMed Central

- yours - you keep the copyright 